\title{
A cross sectional analysis of eating habits and weight status of university students in urban Cameroon
}

\author{
Loveline L. Niba ${ }^{1,2^{*}}$, Mary B. Atanga ${ }^{3}$ and Lifoter K. Navti ${ }^{1,2}$
}

\begin{abstract}
Background: The changeover from high school to university is characterized by the inability to make informed food choices and unhealthy eating habits. This study sets out to determine the prevalence of overweight/obesity, examine variations in dietary habits and assess the relationships between some dietary factors and overweight/ obesity in university students.

Methods: University students ( $N=906$, mean age $21.4 \pm 2.1$ years) that included 434 males and 472 females were recruited using a simple random sampling technique from six departments in two universities in a cross sectional study in the North West Region of Cameroon. Weight and height were measured and body mass index calculated. Eating habits and weekly consumption of selected food items were self-reported by the students using a pre-tested questionnaire.

Results: The prevalence of overweight and obesity were $24.6 \%$ and $2.2 \%$ respectively. A majority (60.7\%) of the students had less than three meals a day. Also, 53.4\% ate fried foods, $46.0 \%$ had sweets/chocolates and $39.5 \%$ had sugar sweetened beverages twice or more times in a week. Skipping/rarely having breakfast (OR 1.8, 95\% Cl 1.2-2.9) and having snacks in-between meals three or more times a day $(\mathrm{OR} 2.2,95 \% \mathrm{Cl}$ 1.4-5.5) were associated with overweight/obesity after controlling for confounding variables. In addition, skipping/rarely having breakfast (OR $2.2,95 \% \mathrm{Cl} 1.3-3.5)$ independently predicted overweight/obesity in a model that included confounding variables and selected dietary behaviors.

Conclusion: The unhealthy eating habits exhibited by students in this study is worrying. Qualitative studies need to be carried out in the future to identify determinants (of Cameroon ethnicity) of poor eating habits in university students.
\end{abstract}

Keywords: Overweight, Obesity, University students, Eating habits, Body mass index

\section{Background}

The dramatic increase in the number of individuals with overweight/obesity in developing countries is concerning. A study among sub-Saharan African children and youth demonstrated that this increase is similar to that of developed countries [1], while another has indicated a higher relative increase $(+65 \%)$ in developing countries than developed countries $(+48 \%)$ [2]. In Cameroon, the numbers of individuals

\footnotetext{
* Correspondence: lumnyanga@gmail.com

${ }^{1}$ Department of Biochemistry, Catholic University of Cameroon (CATUC) BamendaP.O. Box 782Cameroon

${ }^{2}$ Nutrition and Health Research Group (NHRG), Bamenda, Cameroon

Full list of author information is available at the end of the article
}

affected is on the rise and also remains a challenge. A survey that included participants, aged 15 years and over in four urban settings of Cameroon showed that $25 \%$ of men and almost half of the women were either overweight or obese [3]. Kiawi et al. [4] in another study in both rural and urban settings in the North West Region (NWR) of Cameroon estimated the prevalence of overweight and obesity to be $23.6 \%$ and $6.1 \%$ respectively. In addition, the Health of Populations in Transition Research Group in Cameroon revealed that in Bamenda (an urban setting and capital of the NWR), $33.6 \%$ and $23.3 \%$ of the 
study population were overweight and obese respectively [5].

There is enormous evidence indicating the contribution of a high body mass index (BMI $\geq 25 \mathrm{~kg} / \mathrm{m}^{2}$ ) to some non-communicable diseases including type 2 diabetes [6], asthma [7], hypertension [8], cardiovascular diseases [9], stroke [10] and certain cancers [11]. A WHO report of 2014 indicates that the noncommunicable diseases mentioned above accounted for approximately $31 \%$ of total deaths in Cameroon [12]. With respect to the above diseases, earlier reports in Cameroon also indicated that between 1994 and 2003, the age adjusted prevalence of overweight including obesity (BMI $\geq 25 \mathrm{~kg} / \mathrm{m}^{2}$ ) increased significantly by $54 \%$ and $82 \%$ for men and women respectively $[13,14]$. Over the same period, there was a $12.1 \%$ and $15.2 \%$ increase in age-adjusted prevalence of hypertension among women and men respectively [15], and a 10 fold increase in prevalence of diabetes among adults [16, 17]. However, these studies did not include the same subjects.

As young adults move from high school to an independent life in the university, they take full responsibility of their eating habits and most often, they have little or no guidance on how to make informed choices of the food they eat [18]. Many studies in different countries have been carried out to examine the effects of dietary factors on the weight status of young adults in the university. For instance, a US study revealed that there was a significant increase in consumption of alcohol and foods with a high fat content among university students [19]. Also, other studies have indicated a frequent intake of snacks (in-between meals) [20], sugar sweetened beverage [21] and smoking [22] among students. There is consistent evidence demonstrating the relationship between high consumption of sugar sweetened beverages and weight gain [23], but it is still a debate if reducing the intake of sugar sweetened beverages can lead to weight loss [24]. In addition, studies have reported that skipping meals, especially breakfast was common among Malaysian [25] and Italian university students [26]. Data on the eating habits in a university student population is scarce in Cameroon. Overweight and obesity is equally of much importance in this group because Silliman et al. [27] and Crombie et al. [28] have pointed out that during university life, students may acquire unhealthy nutritional habits that are linked to obesity, which may persist into adulthood.

This aim of this study is to determine the prevalence of overweight/obesity, examine variations in eating habits of the study population and assess the relationship between some dietary patterns (commonly observed among university students in previous studies) and overweight/obesity.

\section{Methods}

\section{Subjects}

This institution-based cross sectional analysis included a student sample from two universities (one public and one private) in Bamenda, NWR of Cameroon. Three departments were selected at random in each institution and lists that included first, second and third year students were obtained from each head of department. These lists were used to select students using a simple random sampling technique. An arrangement was made with each head of department and lecturers and the selected students were approached in their classroom immediately after lectures.

A total of 1310 students were selected and 1102 accepted to participate in the study. However, 196 students were dropped because of missing data, and the analysis finally included 906 students of mean age $21.4 \pm 2.1$ years ( $47.9 \%$ males and $52.1 \%$ females). The criteria used to exclude participants from the study included; pregnancy and breastfeeding.

\section{Ethical considerations}

Ethical clearance was obtained from the institutional review board of the Catholic University of Cameroon (CATUC), Bamenda. Also, administrative clearance was obtained from the North West Regional Delegation for Public Health, Bamenda. The main objective of the study was explained to the participants and written informed consent obtained from each of them before data collection. They were told that their participation is voluntary.

\section{Anthropometry}

The measurements were all campus-based (during the 2015/2016 academic year) and carried out by trained personnel, whose activities were in compliance with standard protocols. Standing height measurements (to the nearest $0.1 \mathrm{~cm}$ ) were carried out with a portable stadiometer (Seca 213, Germany) without shoes. Body weight of participants (to the nearest $0.1 \mathrm{~kg}$ ) was obtained using a portable digital scale (Omron BF 511, Japan) in light clothing and without shoes. The height and weight measurements were then used to calculate BMI (in $\mathrm{kg} / \mathrm{m}^{2}$ ) as a measure of the weight status of participants. The WHO criteria on BMI was used to classify participants as underweight $\left(\mathrm{BMI} \leq 18.5 \mathrm{~kg} / \mathrm{m}^{2}\right)$, healthy weight (BMI $18.5-24.9 \mathrm{~kg} / \mathrm{m}^{2}$ ), overweight (BMI $\left.25.0-29.9 \mathrm{~kg} / \mathrm{m}^{2}\right)$ and obese $\left(B M I \geq 30.0 \mathrm{~kg} / \mathrm{m}^{2}\right)$ [29].

\section{Food habits}

As soon as anthropometric measurements were completed on each participant, they were given a pre-tested questionnaire and instructed on how to complete it. This questionnaire had been pre-tested in a group of 35 university students. In the absence of studies that 
examine dietary habits of university students in our setting, it was not possible to carry out any test of validity of the questionnaire. However, the questionnaire was developed by making use of previous studies that examined the dietary habits of university students in other countries $[20,21,30]$. The questionnaire collected selfreported information on age, gender, dietary behaviors/ characteristics, and eating habits. The dietary characteristics section included questions on smoking status, alcohol intake, having a specific dietary regimen, presence of a chronic disease, frequency of eating at the university, number of meals in a day and the purchase of food. Smoking was categorized as: non-smoker, current smoke and ex-smoker. Alcohol intake was categorized as: never, rarely and 2 to 3 times per week. The response option for having a specific dietary regimen and presence of a chronic disease was 'yes' or 'no'. Frequency of eating at the university was categorized as: 3 or more times a week, 1 to 2 times a week and never. The number of meals in a day was categorized as: one, two, three and more than three. Purchase of food was categorized as: food bought already cooked and raw food purchased and self-cooked.

The eating habits section included questions on the frequencies of having breakfast, eating while watching TV, snacks in-between meals in a day and fruit and vegetable intake. It also had a question on when participants stop eating. Having breakfast was categorized as: daily, 3 to 4 times a week, 1 to 2 times a week and skip/ rarely. Eating while watching $\mathrm{TV}$ was categorized as: always, sometimes and never. Snacks in-between meals in a day was categorized as: once, twice, thrice and greater than three times. Fruit and vegetable consumption was categorized as: everyday, occasionally and never. When participants stop eating was categorized as: before fullness, at fullness and more than fullness. The participants also indicated the frequency of consumption of selected food items, which are popular among university students in Bamenda. These food items included: rice, bread, spaghetti, beans, fried Irish potatoes, fried plantain, sugar sweetened beverages, margarine, sweets/chocolate, cakes, meat/fish and eggs. The response option for the selected food items where: $\leq$ once/ week, 2 to 4 times/week and $\geq 5$ times/week.

\section{Statistical analysis}

Statistical analysis was carried out using IBM SPSS (version 21.0). The findings of the dietary behaviors/characteristics and assessment of dietary habits of participants were reported as numbers (\%). The relationships between variables were reported as odds ratios with their corresponding confidence intervals. Normality was checked using Kolmogorov Smirnov $(\mathrm{K}-\mathrm{S})$ test. Also, a Chi square test was used to assess any significant differences in the consumption of selected food items between males and females. In addition, odds ratios were calculated using multivariable binary logistic regression analysis with overweight/obesity as dependent variable. The first step included models that assessed the relationship between each determinant and overweight/obesity and the corresponding odds ratios adjusted for age, gender, smoking, alcohol consumption, chronic disease, dietary regimen and type of institution (public and private). In the second step, odds ratios were adjusted for the above confounding variables and selected dietary behaviors (breakfast consumption, snacks in-between meals, eating while watching $\mathrm{TV}$, fruits and vegetables consumption and when to stop eating). As a measure to ensure stability of the model, the standard errors were monitored so that they do not inflate by more than $10 \%$ when adding more variables in the model during the logistic regression analysis. Lastly, statistically significant differences were considered at $p<0.05$.

\section{Sample size and power calculation}

A major feature of the analysis in this study was the comparisons between males and females. $\mathrm{R}$ was used to compute the sample size with a power of $80 \%$, using a two-sided test at the $5 \%$ level in order to detect a mean difference in BMI of $1.0 \mathrm{~kg} / \mathrm{m}^{2}$ between males and females with a standard deviation of 4.1 [20]. The minimum sample required was 265 in each group, giving a total of 530 .

\section{Results}

The distribution of BMI and dietary characteristics of the investigated population is indicated in Table 1 . The prevalence of overweight and obesity in this study were $24.6 \%$ and $2.2 \%$ respectively. More females were overweight (27.5\%) than males (21.4\%). However, obesity estimates were higher among males (2.5\%) than females (1.9\%). The majority (69.9\%) of the students had a healthy weight.

Smoking was not common in our sample of students. However, more boys consumed alcohol than girls. A majority of the students ate at least once a week at the university with girls representing a higher proportion. Also, only $34.9 \%$ of study participants had three meals a day. Table 1 also shows that more boys purchased readyprepared meals served in a restaurants than girls. Within the investigated population, majority $(86.9 \%)$ of the students bought raw food and cooked it by themselves.

Table 2 compares the eating habits of males and females with respect to selected food items deemed to be popular among students in higher institutions of learning in Bamenda. The most frequently consumed food items (twice or more a week) by the students were bread followed by rice and then meat/fish, eggs and 
Table 1 Gender distribution of dietary characteristics of a randomly selected sample of students at two universities in Bamenda, North West Region of Cameroon $(N=906)$

\begin{tabular}{|c|c|c|c|c|}
\hline \multirow[t]{3}{*}{ Variables } & \multicolumn{2}{|c|}{ Males } & \multicolumn{2}{|c|}{ Females } \\
\hline & \multicolumn{2}{|c|}{$N=434$} & \multicolumn{2}{|c|}{$N=472$} \\
\hline & $\bar{n}$ & $\%$ & $n$ & $\%$ \\
\hline \multicolumn{5}{|l|}{ Body mass index } \\
\hline Underweight & 13 & 3.0 & 17 & 3.6 \\
\hline Healthy weight & 315 & 72.6 & 307 & 65.0 \\
\hline Overweight/obese & 106 & 24.4 & 148 & 31.4 \\
\hline \multicolumn{5}{|l|}{ Smoking status } \\
\hline Non smoker & 393 & 90.5 & 461 & 97.7 \\
\hline Current smoker & 25 & 5.8 & 11 & 2.3 \\
\hline Ex-smoker & 16 & 3.7 & 0 & 0.0 \\
\hline \multicolumn{5}{|l|}{ Alcohol intake } \\
\hline Never & 116 & 26.7 & 164 & 34.7 \\
\hline Rarely & 231 & 53.2 & 273 & 57.8 \\
\hline Two or more times a week & 87 & 20.1 & 35 & 7.4 \\
\hline \multicolumn{5}{|l|}{ Dietary regimen } \\
\hline Yes & 30 & 6.9 & 42 & 8.9 \\
\hline No & 404 & 93.1 & 430 & 91.1 \\
\hline \multicolumn{5}{|l|}{ Chronic disease } \\
\hline Yes & 28 & 6.5 & 26 & 5.5 \\
\hline No & 406 & 93.5 & 446 & 94.5 \\
\hline \multicolumn{5}{|l|}{ Eating at the university } \\
\hline Three or more times a week & 154 & 35.5 & 150 & 32.2 \\
\hline One to two times a week & 170 & 39.2 & 236 & 50.0 \\
\hline Never & 110 & 25.3 & 84 & 17.8 \\
\hline \multicolumn{5}{|l|}{ Meals per day } \\
\hline One & 36 & 8.3 & 22 & 4.7 \\
\hline Two & 217 & 50.0 & 275 & 58.3 \\
\hline Three & 167 & 38.5 & 149 & 31.6 \\
\hline Greater than three & 14 & 3.2 & 26 & 5.5 \\
\hline \multicolumn{5}{|l|}{ Purchase of food } \\
\hline Ready-prepared meals & 94 & 21.7 & 24 & 5.1 \\
\hline Raw food and self-cooked & 340 & 78.3 & 448 & 94.9 \\
\hline
\end{tabular}

sugar sweetened beverages; while the least was spaghetti. There was a significant difference in consumption of rice and bread between males and females. More males ate rice and bread five or more times a week compared to females. However, there was no significant difference in the consumption of meat/fish and eggs by gender.

Also, the consumption of margarine, sweets/chocolate and cakes were significantly different between males and females. More males (18.7\%) ate margarine at least twice a week compared to females (14.8\%). Similarly a higher proportion of males (31.5\%) consumed cakes at least twice a week than females (21.4\%). On the contrary, more than half of the female population (53.2\%) reported consuming sweets/ chocolate twice or more times a week compared to males (38.2\%). A significant difference in the consumption of fried foods by gender was reported for fried Irish potatoes. More than half (53.4\%) of the participants ate fried foods (fried Irish potatoes and plantain) twice or more times a week. The consumption of fried food five or more times a week was more common among females (9.5\%) than males (6.2\%).

Even though the consumption of sugar sweetened beverages (twice or more times a week) was common among the students (39.5\%), there was no significant difference between males and females. The proportion of those who consumed beans at least twice a week was significantly higher for males (23.5\%) than females $(17.8 \%)$.

The relationships between overweight/obesity and potential factors is shown in Table 3. In the first set of models that controlled for age, gender, smoking, alcohol consumption, chronic disease, dietary regimen and type of institution, the habit of skipping/rarely having breakfast and having snacks (in-between meals) three or more times a day were significantly associated to overweight/obesity. However, eating while watching $\mathrm{TV}$, fruit and vegetable consumption and when to stop eating were not significantly associated to overweight/obesity. Also, after controlling for the above confounding variables and selected dietary behaviors (breakfast consumption, snacks in-between meals, eating while watching $\mathrm{TV}$, fruits and vegetables consumption and when to stop eating), skipping/ rarely having breakfast was an independent predictor of overweight/obesity.

\section{Discussion}

This study was designed to determine the prevalence of overweight and obesity, examine the differences in dietary habits of the study population and also assess the relationship between dietary factors and overweight/obesity. It has shown that more than a quarter of the university students were overweight/obese. Similar findings were reported by other studies in Malaysia [31], Jordan [32], Iran [33] and Saudi Arabia [34]. Also, higher prevalence estimates have been reported in the US [35], Kuwait [36] and United Arab Emirates [37], while a Nigerian study reported lower estimates [38]. These differences could be as a result of socio-cultural disparities, which may affect the lifestyle, food habits and health behavior of the students [33], differences in sampling techniques, sample sizes of studies and to some extent on how the data were collected. For instance, height and weight in some 
Table 2 Gender differences in the frequency of consumption of selected food items among a randomly selected sample of students at two universities in Bamenda, North West Region of Cameroon ( $N=906)$

\begin{tabular}{|c|c|c|c|c|c|c|}
\hline \multirow[t]{3}{*}{ Food items } & \multirow[t]{3}{*}{ Frequency } & \multirow{2}{*}{\multicolumn{2}{|c|}{$\begin{array}{l}\text { Males } \\
N=434\end{array}$}} & \multirow{2}{*}{\multicolumn{2}{|c|}{$\begin{array}{l}\text { Females } \\
N=472\end{array}$}} & \multirow[t]{3}{*}{$p$-value } \\
\hline & & & & & & \\
\hline & & $\mathrm{n}$ & $\%$ & $\mathrm{n}$ & $\%$ & \\
\hline \multirow[t]{3}{*}{ Rice } & Less than once a week & 50 & 11.5 & 94 & 19.9 & \multirow[t]{3}{*}{$\leq 0.001$} \\
\hline & 2 to 4 times a week & 251 & 57.8 & 265 & 56.1 & \\
\hline & 5 or more times a week & 133 & 30.6 & 113 & 23.9 & \\
\hline \multirow[t]{3}{*}{ Bread } & Less than once a week & 68 & 15.7 & 100 & 21.2 & \multirow[t]{3}{*}{$\leq 0.001$} \\
\hline & 2 to 4 times a week & 217 & 50.0 & 259 & 54.9 & \\
\hline & 5 or more times a week & 149 & 34.3 & 113 & 23.9 & \\
\hline \multirow[t]{3}{*}{ Spaghetti } & Less than once a week & 381 & 87.8 & 431 & 91.3 & \multirow[t]{3}{*}{0.10} \\
\hline & 2 to 4 times a week & 32 & 7.4 & 30 & 6.4 & \\
\hline & 5 or more times a week & 21 & 4.8 & 11 & 2.3 & \\
\hline \multirow[t]{3}{*}{ Beans } & Less than once a week & 332 & 76.7 & 389 & 82.4 & \multirow[t]{3}{*}{0.05} \\
\hline & 2 to 4 times a week & 85 & 19.6 & 75 & 15.9 & \\
\hline & 5 or more times a week & 17 & 3.9 & 8 & 1.7 & \\
\hline \multirow[t]{3}{*}{ Fried Irish potatoes } & Less than once a week & 287 & 66.1 & 267 & 56.6 & \multirow[t]{3}{*}{0.01} \\
\hline & 2 to 4 times a week & 128 & 29.5 & 176 & 37.3 & \\
\hline & 5 or more times a week & 19 & 4.4 & 29 & 6.1 & \\
\hline \multirow[t]{3}{*}{ Fried plantain } & Less than once a week & 376 & 86.8 & 399 & 84.5 & \multirow[t]{3}{*}{0.28} \\
\hline & 2 to 4 times a week & 50 & 11.5 & 58 & 12.3 & \\
\hline & 5 or more times a week & 8 & 1.8 & 15 & 3.2 & \\
\hline \multirow[t]{3}{*}{ Sugar sweetened beverages } & Less than once a week & 279 & 64.3 & 271 & 57.3 & \multirow[t]{3}{*}{0.11} \\
\hline & 2 to 4 times a week & 125 & 28.8 & 161 & 34.2 & \\
\hline & 5 or more times a week & 30 & 6.9 & 40 & 8.5 & \\
\hline \multirow[t]{3}{*}{ Margarine } & Less than once a week & 354 & 81.5 & 408 & 86.4 & \multirow[t]{3}{*}{$\leq 0.001$} \\
\hline & 2 to 4 times a week & 52 & 12.0 & 60 & 12.7 & \\
\hline & 5 or more times a week & 28 & 6.5 & 4 & 0.8 & \\
\hline \multirow[t]{3}{*}{ Sweets/ chocolate } & Less than once a week & 269 & 61.9 & 221 & 46.7 & \multirow[t]{3}{*}{$\leq 0.001$} \\
\hline & 2 to 4 times a week & 124 & 28.6 & 190 & 40.3 & \\
\hline & 5 or more times a week & 41 & 9.4 & 61 & 13.0 & \\
\hline \multirow[t]{3}{*}{ Cakes } & Less than once a week & 279 & 68.6 & 372 & 78.8 & \multirow[t]{3}{*}{$\leq 0.001$} \\
\hline & 2 to 4 times a week & 109 & 25.2 & 91 & 19.3 & \\
\hline & 5 or more times a week & 27 & 6.2 & 9 & 1.9 & \\
\hline \multirow[t]{3}{*}{ Meat/ fish } & Less than once a week & 143 & 32.9 & 145 & 30.7 & 0.08 \\
\hline & 2 to 4 times a week & 170 & 39.2 & 218 & 46.2 & \\
\hline & 5 or more times a week & 121 & 27.9 & 109 & 23.1 & \\
\hline Eggs & Less than once a week & 148 & 34.1 & 178 & 37.7 & 0.33 \\
\hline & 2 to 4 times a week & 214 & 49.3 & 230 & 48.7 & \\
\hline & 5 or more times a week & 72 & 16.6 & 64 & 13.6 & \\
\hline
\end{tabular}

studies were measured, while in others these variables were self-reported.

The eating habits of having less than three meals a day and frequent consumption of fried foods, sweets/ chocolates, sugar sweetened beverages and cakes observed in this study could be as a result of convenience and the availability of these items along the streets and in university canteens. The less frequent consumption of fruits and vegetables among the students could be explained by the high prices 
Table 3 Odds of overweight/obesity associated with selected dietary behaviors among a randomly selected sample of students at two universities in Bamenda, North West Region of Cameroon $(N=906)$

\begin{tabular}{|c|c|c|c|c|c|c|c|c|}
\hline \multirow[t]{2}{*}{ Determinants } & \multirow[t]{2}{*}{ N } & \multicolumn{7}{|c|}{ Overweight/obesity } \\
\hline & & Frequency (\%) & Step 1 Adjusted OR ${ }^{a}$ & $(95 \% \mathrm{Cl})$ & $p$-value & Step 2 Adjusted OR ${ }^{\mathrm{b}}$ & $(95 \% \mathrm{Cl})$ & $p$-value \\
\hline \multicolumn{9}{|l|}{ Breakfast consumption } \\
\hline Skip/rarely & 242 & 23.6 & 1.8 & $(1.2-2.9)$ & 0.01 & 2.2 & $(1.3-3.5)$ & 0.002 \\
\hline One to two times a week & 142 & 36.6 & 1.2 & $(0.8-1.9)$ & 0.39 & 1.3 & $(0.8-2.1)$ & 0.22 \\
\hline Three to four times a week & 208 & 26.9 & 1.1 & $(0.7-1.6)$ & 0.63 & 1.2 & $(0.8-1.8)$ & 0.51 \\
\hline Daily & 314 & 24.5 & Ref & & & Ref & & \\
\hline \multicolumn{9}{|l|}{ Snacks (in-between meals) } \\
\hline Greater than 3 times a day & 68 & 20.5 & 2.2 & $(1.4-5.5)$ & 0.04 & 2.2 & $(0.9-5.7)$ & 0.10 \\
\hline Three times a day & 36 & 33.3 & 1.1 & $(0.5-2.3)$ & 0.77 & 0.9 & $(0.4-2.0)$ & 0.81 \\
\hline Twice a day & 134 & 23.9 & 1.4 & $(0.8-2.6)$ & 0.27 & 1.5 & $(0.8-2.9)$ & 0.22 \\
\hline Once a day & 668 & 27.5 & Ref & & & Ref & & \\
\hline \multicolumn{9}{|l|}{ Eating while watching TV } \\
\hline Always & 160 & 30.6 & 0.8 & $(0.5-1.4)$ & 0.44 & 0.6 & $(0.4-1.1)$ & 0.09 \\
\hline Sometimes & 660 & 25.3 & 1.1 & $(0.6-2.0)$ & 0.68 & 1.0 & $(0.5-1.8)$ & 0.96 \\
\hline Never & 86 & 30.2 & Ref & & & Ref & & \\
\hline \multicolumn{9}{|c|}{ Fruits and vegetables consumption } \\
\hline Never/occasionally & 658 & 28.3 & 0.9 & $(0.6-1.3)$ & 0.56 & 0.9 & $(0.5-1.3)$ & 0.49 \\
\hline Everyday & 248 & 26.2 & Ref & & & Ref & & \\
\hline \multicolumn{9}{|l|}{ When to stop eating } \\
\hline More than fullness & 68 & 32.4 & 0.7 & $(0.4-1.1)$ & 0.14 & 0.7 & $(0.3-1.4)$ & 0.32 \\
\hline At fullness & 670 & 26.1 & 0.7 & $(0.4-1.3)$ & 0.27 & 0.7 & $(0.4-1.2)$ & 0.21 \\
\hline Before fullness & 168 & 26.8 & Ref & & & Ref & & \\
\hline
\end{tabular}

$\mathrm{OR}$, odds ratio; $\mathrm{Cl}$, confidence interval

${ }^{a}$ Odds ratios have been adjusted for the following confounding variables: age, gender, smoking, chronic disease, having a dietary regimen and type of institution ${ }^{b}$ Odds ratios have been adjusted for the above confounding variables as well as breakfast consumption, snacks in-between meals, eating while watching TV, fruits and vegetables consumption and when to stop eating

especially in the dry season. Also, the consumption of raw vegetables and fruits alongside main meals is not a common practice in the student population.

This unhealthy picture is typical of a university student population as demonstrated in previous studies which identified poor dietary behavior among university student samples in Jordan [32] and Nigeria [39]. In addition, a report by Al-Rethaiaa et al. [40] revealed that most of the students had two meals a day, with frequent consumption of fried foods and snacks, and less frequent consumption of fruits and vegetables. However, a study in Finland showed that most university students adhere to the dietary guidelines of consumption of cakes, fruits, vegetables, fast foods and sugar sweetened beverages [30].

Some studies had identified potential determinants that could explain the poor eating habits of university students. For instance, a recent study that included a student sample from 40 German universities identified high food prices, lack of time and absence of healthy foods in the university canteen as factors that influence healthy eating
[41]. Even though there is no documented evidence, a majority of Cameroon university students do not work, and they rely on their parents' support throughout university studies. Those from a low income background might not be able to afford three healthy meals in a day. In addition, a majority of students spend most of their time on campus and have limited time to prepare a healthy meal for themselves, especially during examination periods [42] and thus rely on confectioneries that form the bulk of foods available in university canteens.

Nutrition knowledge had been identified as an additional factor that could explain poor eating habits among university students [42]. This study did not assess nutrition knowledge. However, a US study revealed that only $4 \%$ of a university student population had good nutritional knowledge [43]. Thus a limited nutrition knowledge could explain to some extent the unhealthy dietary habits observed in this study.

However, the last two studies were each carried out in one university and there could have been some degree of selection bias as the studies made use of volunteers. 
The high frequency of consumption of rice, bread, eggs and meat/fish especially among the males observed in this study could be because these food items are more convenient/require minimal preparation. The consumption of these food items were also common among students in Saudi Arabia [21]. However, this study included only female subjects from one university. Eggs was also frequently consumed because it is easily affordable and fried eggs with bread or fried potatoes/plantains or spaghetti are popular combinations eaten by the students. Additionally, rice and stew (including meat, fish or chicken and vegetable) is another popular dish among university students. Beans is usually eaten with rice or fried plantains. However, the low consumption of beans by students in this study could be because beans is bought raw and takes a longer time prepare.

Skipping/rarely having breakfast and having snacks (inbetween meals) three or more times in a day were associated with overweight/obesity. Evidence has shown that when people skip breakfast, there is a tendency that their snacks intake will be higher during the day, which could lead to a positive energy balance and weight gain [44]. However, a study indicated no relationship between frequency of breakfast intake and overweight/obesity [45] and the contribution of snacks to a higher BMI is still a subject of debate [41].

This study had limitations. Some subjects had to be dropped because of missing data. However, there were no significant differences in anthropometric variables between those dropped and those retained in the study. Also, the standard errors might have been underestimated as a result of the fact that a simple random sampling technique was used to recruit participants. The possibility of selection bias cannot be ruled out because students participated on a voluntary basis. The information on dietary habits and weekly consumption of foods were self-reported and could have been subjected to recall bias. Our study included participants from one out of the ten administrative regions of the country. Thus, the findings may not be representative of the university student population of the whole country. Elements of causality cannot be established as a result of the cross sectional nature of the study. Additionally, physical activity and calorie intake, which are important determinants of overweight/obesity were not assessed. Nevertheless, this study had some strengths. It included students from two universities as opposed to one university as reported in other studies [20,21, 25, 26, 30, 32, 33, 37, 42]. The study population included a mix of students from different socioeconomic backgrounds because it included students from both a state and a private university. In Cameroon, students in private institutions are usually of a higher socioeconomic background compared to those in state institutions because of the higher tuition fees in private institutions. This could have eliminated the confounding effect of socioeconomic status to a certain degree.

\section{Conclusion}

More than a quarter of the study participants were overweight/obese, and majority had a healthy weight. This study has demonstrated that students who skip/rarely have breakfast tend to have higher odds of overweight/ obesity. It has also revealed that majority of the students had less than three meals a day and chose the unhealthy food options. In the future, it is important for studies to consider the use of a qualitative approach to find out the determinants (of Cameroon ethnicity) that affect eating habits of university students.

\section{Abbreviations \\ BMI: Body mass index; NMR: North West Region; TV: Television; WHO: World Health Organization}

\section{Acknowledgements \\ This study was conducted by the Nutrition and Health Research Group (NHRG) in Bamenda - Cameroon. Also, the authors are grateful to the administration of the institutions as well as the students for accepting to participate in this study.}

\section{Funding \\ The authors funded the study.}

\section{Availability of data and materials}

The datasets used and/or analyzed during the current study are available from the corresponding author on reasonable request.

\section{Authors' contributions}

LLN was responsible for the conception and design of the study, direct collection of data and processing, statistical analysis and drafting of the manuscript. MBSA contributed to the conception and design of the study as well as interpretation and analysis concepts of the data. LKN substantially contributed to the conception and design of the study, participated in data collection, as well as interpretation of data and drafting of manuscript. All authors revised the manuscript and gave a final approval of the submitted version.

\section{Ethics approval and consent to participate}

Ethical clearance was obtained from the institutional review board of the Catholic University of Cameroon (CATUC), Bamenda. Also, administrative clearance was obtained from the North West Regional Delegation for Public Health, Bamenda. Written informed consent was obtained from each participant before data collection.

Consent for publication

Not applicable.

\section{Competing interests}

The authors declare that they have no competing interests.

\section{Publisher's Note}

Springer Nature remains neutral with regard to jurisdictional claims in published maps and institutional affiliations.

\section{Author details}

'Department of Biochemistry, Catholic University of Cameroon (CATUC), BamendaP.O. Box 782Cameroon. ${ }^{2}$ Nutrition and Health Research Group (NHRG), Bamenda, Cameroon. ${ }^{3}$ Department of Nursing and Midwifery, University of Bamenda, P.O. Box 39, Bambili, Bamenda, Cameroon. 
Received: 24 April 2017 Accepted: 6 July 2017

\section{Published online: 11 July 2017}

\section{References}

1. Muthuri SK, Francis CE, Wachira L-JM, LeBlanc AG, Sampson M, et al. Evidence of an overweight/obesity transition among school-age children and youth in sub-Saharan Africa: a systematic review. PLoS One. 2014;9(3): e92846. doi:10.1371/journal.pone.0092846.

2. de Onis M, Blossner M, Borghi E. Global prevalence and trends in of overweight and obesity among preschool children. Am J Clin Nutr. 2010:92:1257-64.

3. Kamadjeu RM, Edwards R, Atanga JS, Kiawi EC, Unwin N, Mbanya JC. Anthropometry measures and prevalence of obesity in urban adult population of Cameroon: an update from the Cameroon burden of diabetes baseline survey. BMC Public Health. 2006;6:228.

4. Kiawi E, Edwards R, Shu J, Unwin K, Kamadjeu RM, Mbanya JC. Knowledge, attitude and behavior relating to diabetes and its main risk factors among urban residents in Cameroon: a qualitative survey. Ethicity and Disease. 2006;16:503-9

5. Health of Populations in Transition Research Group - Cameroon: Cameroon burden of diabetes (CamBoD) project: baseline survey report summary. Ministry of Public Health, Cameroon; 2004

6. James WP, Jason-Leach R, Ni Mburchu C, Kalamara E, Shayeghi M, Rigby NJ, et al. Overweight and obesity (high body mass index). In: Ezzati M, Lopez AD, Rodgers A, Murray CJ, editors. Comparative quantification of health risks: global and regional burden of disease attributable to selected major risk factors, vol1. Geneva: WHO; 2004. p. 497-596.

7. Figueroa-Munoz Jl, Chinn S, Rona RJ. Association between obesity and asthma in $4-11$ year old children in the UK. Thorax. 2001;56(2):133-7.

8. Chiolero A, Madalein G, Gabriel A, Burnier M, Paccaud F, Bover P. Prevalence of elevated blood pressure and association with overweight in children of a rapidly developing country. J Hum Hypertens. 2007;21:120-7.

9. Burke GL, Bertoni AG, Shea S, Tracy R, Watson KE, Blumenthal RS, Chung H Carnethon MR. The impact of obesity on cardiovascular disease risk factors and subclinical vascular disease. The multi-ethnic study of atherosclerosis. Arch Intern Med. 2008;168(9):928-35.

10. Guo Y, Yue XJ, Li HH, Song ZX, Yah HK, et al. Overweight and obesity in young adulthood and risk of stroke: a meta-analysis. J Stroke Cerebrovasc Dis. 2016;25(12):2995-3004.

11. World Health Organization. Obesity: preventing and mapping the global epidemic. Geneva: WHO Technical Report Series number 894; 2000.

12. World Health Organization. NCD Country Profiles 2014. Available from http://apps.who.int/iris/bitstream/10665/128038/1/9789241507509_eng.pdf [Accessed 23 Apr 2017].

13. Dapi LN, Hornell A, Janlert U, Stenlund H, Larison C. Energy and nutrient intakes in relation to sex and socio-economic status among school adolescents in urban Cameroon, Africa. Public Health Nutr. 2010:1-10.

14. Fezeu L, Assah FK, Balkau B, Mbanya DS, Kengne AP, Awah PK, Mbanya JC. Ten-year changes in central adiposity and BMI in rural and urban Cameroon. Obesity (Silver Spring). 2008;16:1144-7.

15. Fezeu L, Kengne AP, Balkau B, Awah PK, Mbanya JC. Ten-year change in blood pressure levels and prevalence of hypertension in rural and urban Cameroon. J Epidemiol Community Health. 2010:64(4):360-5.

16. Assah FK, Mbanya JC. Diabetes in sub-Saharan Africa - overview of a looming health challenge. Eur Endocrinol. 2009:5(1):13-7.

17. Mbanya JC, Kengne AP, Assah F. Diabetes care in Africa. Lancet. 2006; 368(9548):1628-9.

18. Conklin MT, Lambert CU, Cranage DA. Nutrition information at point of selection could benefit college students. Top Clin Nutri. 2005;20(2):90-6

19. Butler SM, Black DR, Blue CL, Gretebeck RJ. Change in diet, physical activity and body weight in female college freshmen. Am J Health Behav. 2004; 28(1):24-32.

20. Yahia N, Achkar A, Abdalla A, Rizk S. Eating habits and obesity among Lebanese university student. Nutr J. 2008;7:13.

21. Al Qauhiz NM. Obesity among Saudi female university students: dietary habits and health behaviors. J Egypt Public Health Assoc. 2010;85(1):45-59.

22. Aceijas C, WaldhausI S, Lambert N, Cassar S, Bello-Corassa R. Determinants of health-related lifestyles among university students. Perspect Public Health. 2016;137(4):227-36.
23. Malik VS, Schulze MB, Hu FB. Intake of sugar-sweetened beverages and weight gain: a systematic review. Am J Clin Nutr. 2006;84(1):274-88.

24. Allison DB, Mattes RD. Nutritively sweetened beverage consumption and obesity. The need for solid evidence on a fluid issue. JAMA. 2009;301:318-20

25. Chin YS, Mohd NM. Eating behaviors among female adolescents in Kuatan District, Pahang, Malaysia. Pak J Nutr. 2009;8(4):425-32.

26. Teleman AA, de Waure C, Soffiani V, Poscia A, Di Pietro ML. Nutritional habits in Italian university students. Ann 1st Super Sanità. 2015;51(2):99-105.

27. Silliman K, Rodas-Fortier K, Neyman M. A survey of dietary and exercise habits and perceived barriers to following a healthy lifestyle in a college population. California J Health Promot. 2004;2(2):10-9.

28. Crombie AP, llich JZ, Dutton GR, Panton LB, Abood DA. The freshman weight gain phenomenon revisited. Nutr Rev. 2009;67(2):83-94.

29. World Health Organization. Obesity: preventing and managing the global epidemic. Report of a WHO consultation. Presented at the WHO, June 3-5, 1997; Geneva, Switzerland. who/nut/ncd/98. 1:1998.

30. El-Ansari WEl, Suominen S, Samara A. Eating habits and dietary intake: is adherence to dietary guidelines associated with importance of healthy eating among undergraduate university students in Finland? Cen Eur J Public Health. 2015;23(4):306-13.

31. Pell C, Allotey P, Evans N, Hardon A, Imelda JD, et al. Coming of age, becoming obese: a cross sectional analysis of obesity among adolescents and young adults in Malaysia. BMC Public Health. 2016;16:1082.

32. Suleiman AA, Alboqai OK, Yasein N, El-Qudah JM, Bataineh MF. Prevalence and factors associated with overweight and obesity Jordan university students. J Biol Sci. 2009;9(7):738-45.

33. Nojomi M, Najamabadi S. Obesity among students, Tehran, Iran. Asia Pac J Clin Nutr. 2006;15(4):516-20.

34. Abdel-Megeid FY, Abdelkarem HM, El-Fetouh AM. Unhealthy nutritional habits in university students are a risk factor for cardiovascular diseases. Saudi Med J. 2011;32(6):621-7.

35. American Heart Association. Overweight and obesity. Statistical fact sheet 2013 update. Available from https://www.heart.org/idc/groups/heart-public/ @wcm/@sop/@smd/documents/downloadable/ucm_319588.pdf [Accessed 23 Apr 2017].

36. Al-Isa AN. Obesity among Kuwait university students: an explorative study. J R Soc Health. 1999:4:223-7.

37. Musaiger AO, Lioyd OL, Bener AB, Al-Neyadi SM. Lifestyle factors associated with obesity among male university students in United Arab Emirates. Nutr Food Sci. 2003:33:145-7.

38. Olusanya JO, Omotayo OA. Prevalence of obesity among undergraduate students of tai Solarin University of Education, ljagun, ljebu-ode. Pakistan $」$ Educ. 2011:10(10):940-6.

39. Otemuyiwa IO, Adewusi SR. Food choice and meal consumption pattern among undergraduate students in two universities in south western Nigeria. Nutr Health. 2012;21:233-45.

40. Al-Rethaiaa AS, Fahmy AA, Al-Shwaiyat NM. Obesity and eating habits among college students in Saudi Arabia: a cross sectional study. Nutr J. 2010;9:39

41. Hilger J, Loerbroks A, Diehl K. Eating behavior of university students in Germany: dietary intake, barriers to healthy eating and changes in eating behavior since the time of matriculation. Appetite. 2016;109:100-7.

42. Deliens T, Clarys P, De Bourdeaudhuij I, Deforche B. Determinants of eating behavior in university students: a qualitative study using focus group discussions. BMC Public Health. 2014;14:53.

43. Yahia N, Wang D, Rapley M, Dey R. Assessment of weight status, dietary habits and beliefs, physical activity, and nutritional knowledge among university students. Perspect Public Health. 2016;136(4):231-44.

44. De Graaf C. Effects of snacks on energy intake: an evolutionary perspective. Appetite. 2006:47:18-23.

45. Abdelhafez AM, Al-Mashi SM. Prevalence of obesity and some related attributes among umm al-Qura University female students in Makkah, Saudi Arabia. Pak J Nutr. 2013:12(3):275-84. 